\title{
Investigation of Coastal Environment Change Using Wave Measurement Sensors and Geographical Laser Scanner
}

\author{
Kyu-Han Kim (D), Bum-Shick Shin, and Kyu-Tae Shim (iD \\ Catholic Kwandong University, 579 Beon-gil, Gangneung-si, Gangwon-do, Republic of Korea \\ Correspondence should be addressed to Kyu-Tae Shim; aiqshim@gmail.com
}

Received 1 February 2019; Accepted 27 March 2019; Published 2 May 2019

Guest Editor: Lei Zhang

Copyright (C) 2019 Kyu-Han Kim et al. This is an open access article distributed under the Creative Commons Attribution License, which permits unrestricted use, distribution, and reproduction in any medium, provided the original work is properly cited.

\begin{abstract}
The construction of large-scale coastal structures in any coastal area may not only have direct effects on the coastal environment in that vicinity but also cause severe property damage. In order to prevent this problem, probable effects should be appreciated before any construction and the mechanism that may cause any probable damage must be accurately analyzed along with the plans to minimize damage. This study sought to analyze the cause and mechanism of damage inflicted on coasts by artificial structures through reviewing beach erosions that have occurred on beaches on the east coast of Korea after the large-scale construction of artificial structures, for which wave heights were measured in the vicinity of those structures, and the correlation between the measurements and the analysis data of waves and coastal erosion on the surrounding beach was analyzed. In addition, the correlation between coastal erosion and wave data was applied in order to understand what impact large waves have in relation to sand loss. Accordingly, a movable-bed physical model test was employed to appraise the factors that cause coastal erosion to take place.
\end{abstract}

\section{Introduction}

The Korean east coast is about $223 \mathrm{~km}$ long and the coastline is fairly uniform in character, with pine forests and sandy beaches together forming a pleasant environment. However, large-scale harbor facilities and power generation sites are constructed through the coastal development promoted by the national or a local government, causing adverse effects on beautiful coastal environments. The wave diffraction occurs due to a newly constructed or extended coastal structures [1] and beach erosion occurs on a place where waves are concentrated, resulting in coastal erosion. Various studies regarding the coastal erosion are being carried out by many researchers, and among them, Liou [1] and Kim and Shim [2] installed a wave height meter on the target area, analyzed annual wave distribution, and studied the relationship between incident abnormal waves and coastal erosion. Klaus [3] and Kim [4] carried out research on sand loss caused by seawall construction and sought to devise and establish measures to reduce such loss. Kim [5] established plans to decrease sand loss by reviewing the appropriateness of construction methods through monitoring the environment after construction. It is also necessary to clarify the causes and countermeasure for beach erosion by measuring, collecting, and summarizing specific and diverse data regarding incident wave and topographical change on each target area. In this study, one location where erosion is taking place as a result of the large-scale construction of a harbor facility on the east coast of Korea was selected and field investigation was conducted to understand how the construction of artificial structures brings about changes in the coastal environment. The heights of waves were measured in the observation field, and the correlation between the coastal erosion taking place in the surrounding beaches and analyzed data on waves was estimated. From the correlation between coastal erosion and wave data, the significant wave data that cause sand loss were derived, and a hydraulic model experiment was carried out on the target coast. Also, the causes and reduction method for currently occurring coastal erosion were examined.

\section{Field Investigation}

2.1. Target Area. The research area was Wolcheon Beach in Samcheok where a large-scale breakwater measuring $1.8 \mathrm{~km}$ in length has been constructed in the $28 \mathrm{~m}$ depth of seawater to promote the smooth operation of a gas production facility. 
TABLE 1: AWAC specifications.

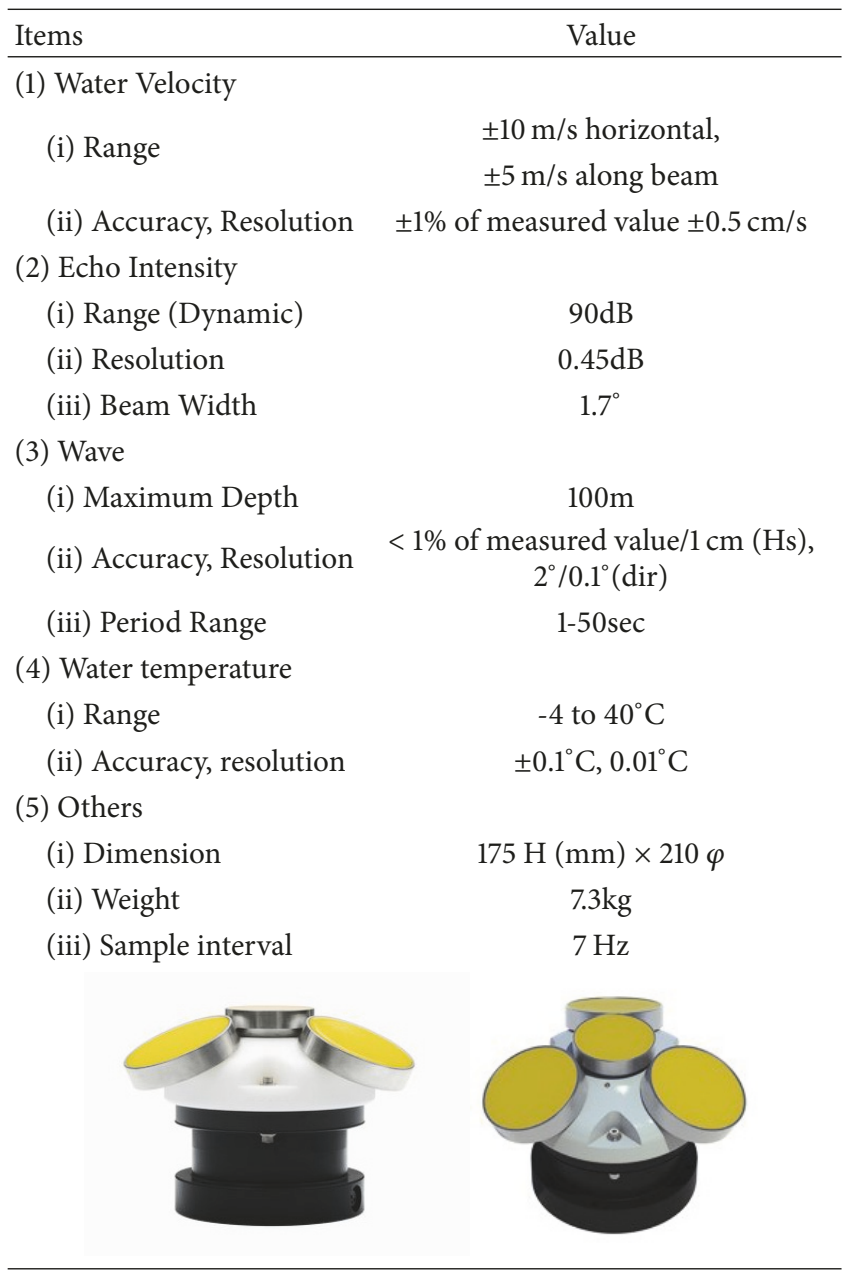

There was sand loss during construction in the area where wave concentration was caused by waves diffraction. After the completion of the construction, there has been damage caused by wave overtopping onto coastal roads and residential areas at the time of high wave attacks. Concrete blocks have been put in place as an emergency measure to protect rear-areas and reduce waves. The loss of sand has negatively impacted the beach and harmed its image as a beach resort, leading to a marked decrease in the number of visitors.

2.2. Wave Observation. In order to investigate the coastal environment, analyze the erosion situation, and anticipate future scenarios, waves were measured at 2 points (W1, W2) as seen in Figure 1. Data from W1 were collected for 73 months from December 2011 to December 2017 while data from W2 was collected for a short period from March 2012 to September 2012. The collected data were employed for the analysis of changes by season and the frequency of abnormal high waves caused by typhoons and formation of abnormal atmospheric pressure troughs. The devices used for wave measuring were different by location. AWAC (Acoustic Wave and Current profiler, Table 1) that was installed for W1 measurement is a memory wave height meter using
TABLE 2: Wave Hunter-301 specifications.

\begin{tabular}{lc}
\hline Items & Value \\
\hline (1) Water Velocity & \\
(i) Range & $\pm 3 \mathrm{~m} / \mathrm{s}$ \\
(ii) Accuracy, resolution & $1 \% / \mathrm{FS}, 1 \mathrm{~cm} / \mathrm{s}$ \\
(iii) Response Speed & $40 \mathrm{msec}$
\end{tabular}

(2) Water Pressure
(i) Range
(ii) Accuracy, resolution

0 to $5 \mathrm{~kg} / \mathrm{cm}$

(3) Azimuth

(i) Range
(ii) Accuracy, resolution $\pm 0.5 \% / \mathrm{FS}, 1 \mathrm{~g} / \mathrm{cm}^{2}$

(4) Water temperature
(i) Range
(ii) Accuracy, resolution

0 to $359^{\circ}$

$\pm 3^{\circ}, 1$

(5) Others
(i) Dimension
(ii) Weight
(iii) Sample interval

\section{-5 to $40^{\circ} \mathrm{C}$ $\pm 0.1^{\circ} \mathrm{C}, 0.1^{\circ} \mathrm{C}$}
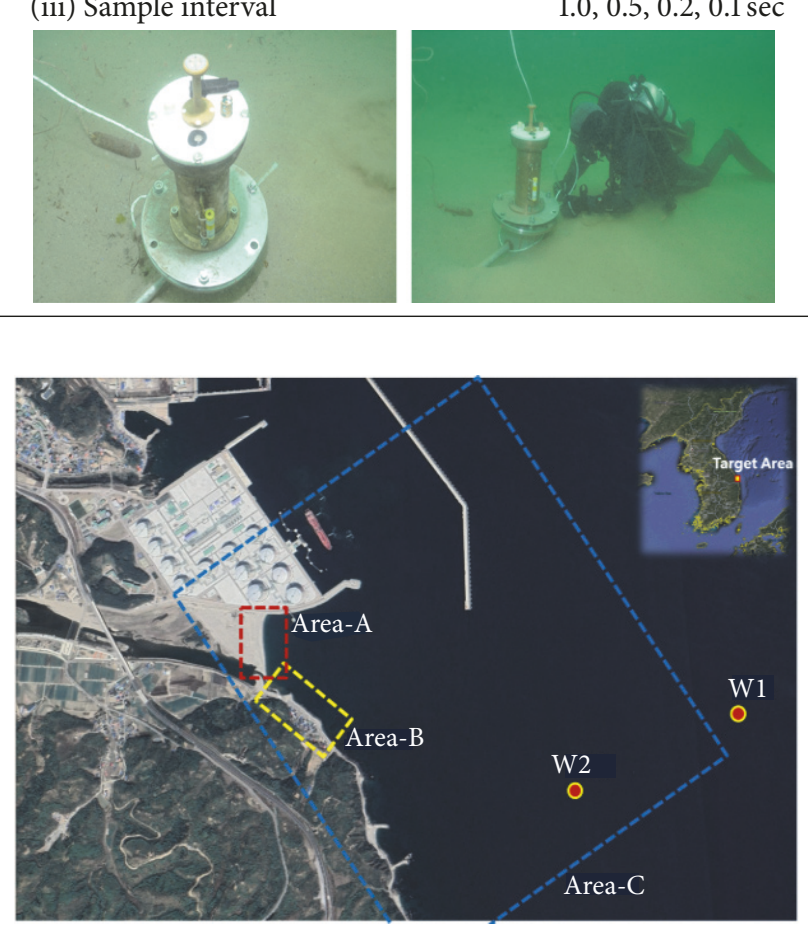

Figure 1: Study Area (Wolcheon Beach, Korea).

ultrasonic waves that enable the simultaneous observation of wave height, wave direction, flow direction, and flow velocity $[6,7]$. The observations were carried out for more than 10 minutes every hour and the time interval between observations was set at $0.5 \mathrm{sec}$.

Wave Hunter-301 (Table 2) employed for W2 is a pressure type, which enables the simultaneous observation of wave height, wave direction, flow direction, and flow velocity [8]. Tables 1 and 2 show the performances of the two wave height meters. 


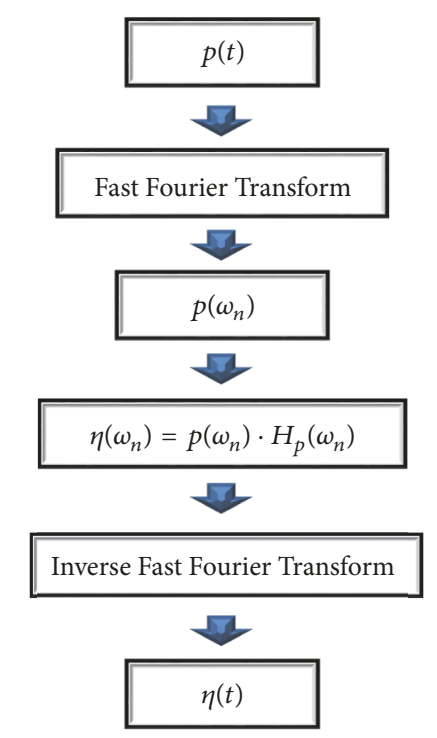

FIGURE 2: Flow of wave data analysis.

Since the hydraulic wave height meter can get the pressure variation data by wave energy, it is needed to convert the pressure variation data to water-level fluctuation so as to get the time series water-level fluctuation waveform. Figure 2 shows the process of converting the pressure data from the pressure sensor to wave height data. Here, $p(t)$ is time series hydraulic pressure variation data, $\mathrm{p}\left(\omega_{\mathrm{n}}\right)$ is hydraulic pressure variation data in the frequency domain, $\eta\left(\omega_{\mathrm{n}}\right)$ is sea-surface variation data in the frequency domain, $\eta(\mathrm{t})$ is time series sea-surface variation data, and $\mathrm{H}_{\mathrm{p}}\left(\omega_{\mathrm{n}}\right)$ is pressure response function by frequency. At Figure 2, the method of FFT (Fast Fourier Transform) is a general method for converting the pressure waveform to the time series of water-level fluctuation, and if irregular waves overlap linear regular-waves, the pressure waveform can be expressed as the overlapping of component waves in the frequency domain by Fourier Transform. If the time series of pressure is $\mathrm{p}(\mathrm{t})$, the component waves in the frequency domain can be described as in (1).

$$
\mathrm{p}\left(\omega_{n}\right)=\rho g \sum_{n=0}^{\infty} A_{n} \cos \left(\omega_{n} t-\varphi_{n}\right)
$$

Here, $\omega_{n}$ and $\varphi_{n}$ are frequency and phase angle, respectively. $A_{n}$ (amplitude) of $\omega_{n}$ is determined by FFT, when the value of the pressure response function from the linear response function is the function of each frequency, and the value of the response function of each frequency can be obtained by (2).

$$
K_{p}\left(\omega_{n}\right)=\frac{\cosh k_{n}(z+h)}{\cosh k_{n} h}
$$

Since the sea-surface waveform also can be described as the sum of component waves in the frequency domain, the seasurface waveform can be estimated as in (3).

$$
\eta\left(\omega_{n}\right)=\sum_{n=1}^{\infty} H_{p\left(\omega_{n}\right)} \cdot A_{n} \cos \left(\omega_{n} t-\varphi_{n}\right)
$$

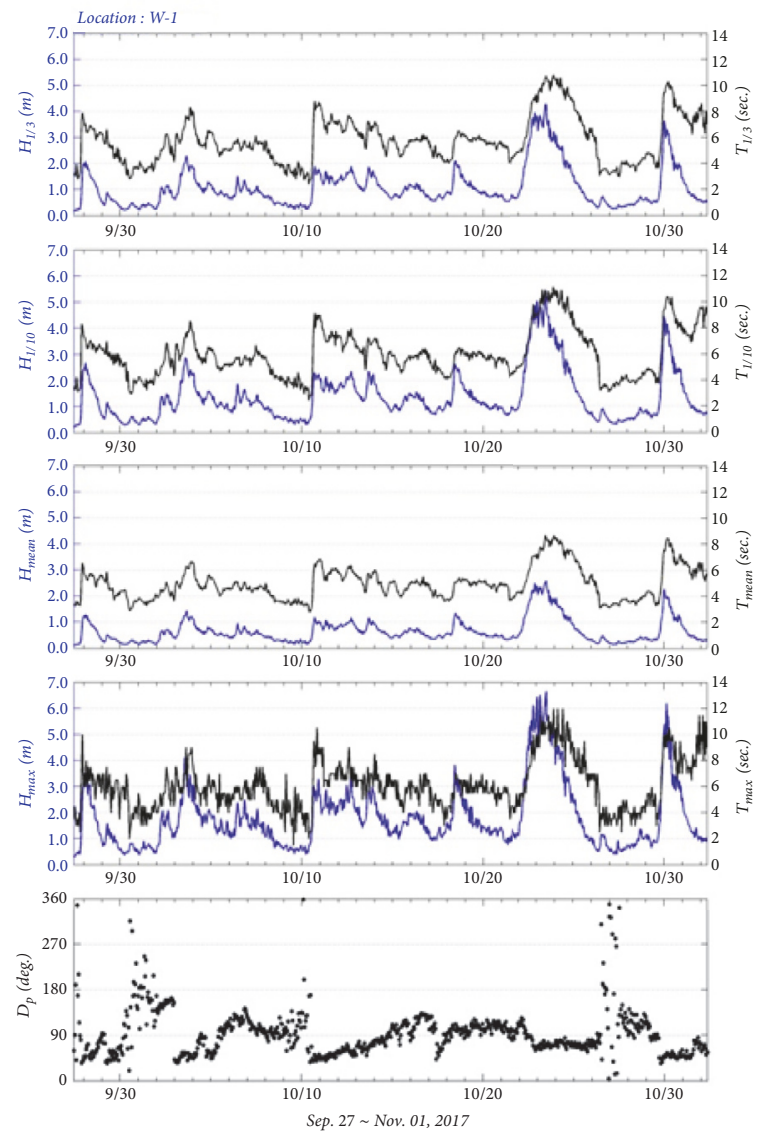

Figure 3: Time series data on W1 (2017.09 11).

Here, $H_{p}\left(\omega_{n}\right)$ can be calculated as in (4).

$$
K_{p}\left(\omega_{n}\right)=\frac{1}{K_{p}\left(\omega_{n}\right)}=\frac{\cosh k_{n} h}{\cosh k_{n}(z+h)}
$$

The time series of water-level fluctuation can be obtained from (3) based on Inverse FFT.

2.3. Wave Observation Results. The analysis results of the data measured at W1 revealed that in autumn (SeptemberDecember) and winter (January-March) high waves occurred frequently toward the target area. The data for autumn with regard to the greatest frequency of high waves are organized in Figures 3-5. Figure 3 shows the time series classified into each class of waves height during the measurement period. The analysis results revealed that most of the significant waves $\left(\mathrm{H}_{1 / 3}\right)$ occurred with an average height of $1 \mathrm{~m}-2 \mathrm{~m}$ for the average significant period $\left(\mathrm{T}_{1 / 3}\right)$ of 6-8 sec.

The maximum wave height and period were $2 \mathrm{~m}-3 \mathrm{~m}$ and 6-8 sec on average, respectively. The significant wave height and period and the maximum wave height and period were employed to describe the appearance rate of waves (Figure 4). The analysis results show that waves with a height less than $1.5 \mathrm{~m}$ occurred most often (over $80 \%$ ) when the wave periods were less than $7 \mathrm{sec}$. Most of the maximum wave heights were $0.5 \mathrm{~m}-2.0 \mathrm{~m}$ when the period was $5-7 \mathrm{sec}$. 

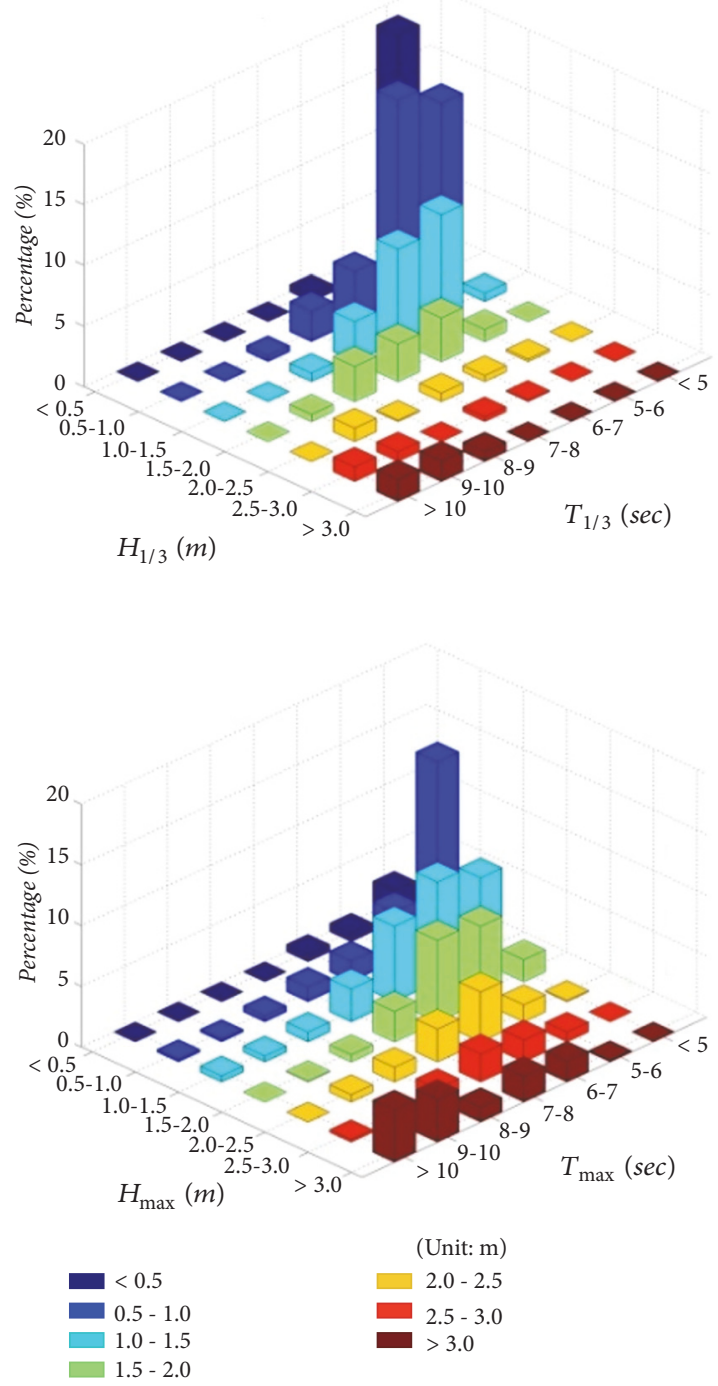

FIgURE 4: Appearance rate of wave height and period on W1 (2017.09 11)

The wave directions were found to be mostly distributed in NE ESE, and among them waves with ENE direction were found to occur the most. These outcomes are related to W1. The data from W2 were obtained for about 3 months from July 01,2012 , to September 25, 2012. The analysis revealed that the high waves that occurred on the fifteenth of July and in September were thought to be the result of the influence of typhoons; other significant waves had heights of $1 \mathrm{~m}$ and significant wave period of less than $3 \mathrm{sec}$. These results are summarized in the time series data with descriptions in Figure 6.

As seen from the observation results, the waves with the highest appearance rate are those that occur in ordinary times. However, while strong diffraction waves and high runup of waves do not occur frequently, they not only cause large amount of sand loss and some other serious damages as a result of wave overtopping but also become a factor behind the acceleration of the erosion phenomenon.
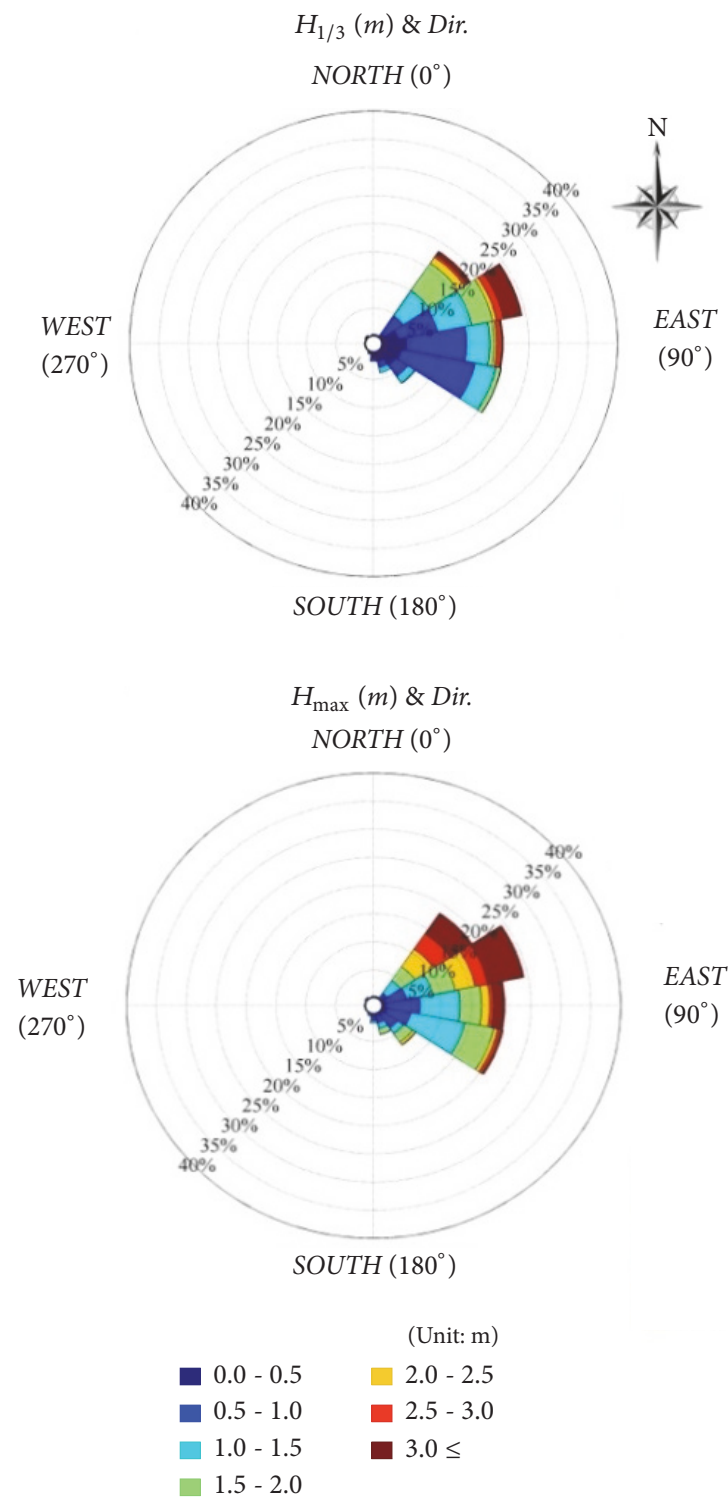

FIGURE 5: Appearance rate of wave height and direction on W1 (2017.09 11).

\section{Physical Model Test}

3.1. Experiment Setup. The analysis of short-term and longterm observations revealed that the incidence of significant waves occurs more often in autumn in comparison to the annual average.

As Figure 5 indicates, since the incidence of abnormally high waves is also marked by longer periods of duration, the coastal environment changes with the large amount of sediment transport when there is any direct influence exerted by enormous wave energy on a beach [9-11]. Moreover, since the increase of duration time causes more serious beach erosion, the prediction of high waves must be accurately anticipated and proper countermeasures should be established [12, 13].

While there are various methods for investigating topographic changes, physical model test is known to draw the 


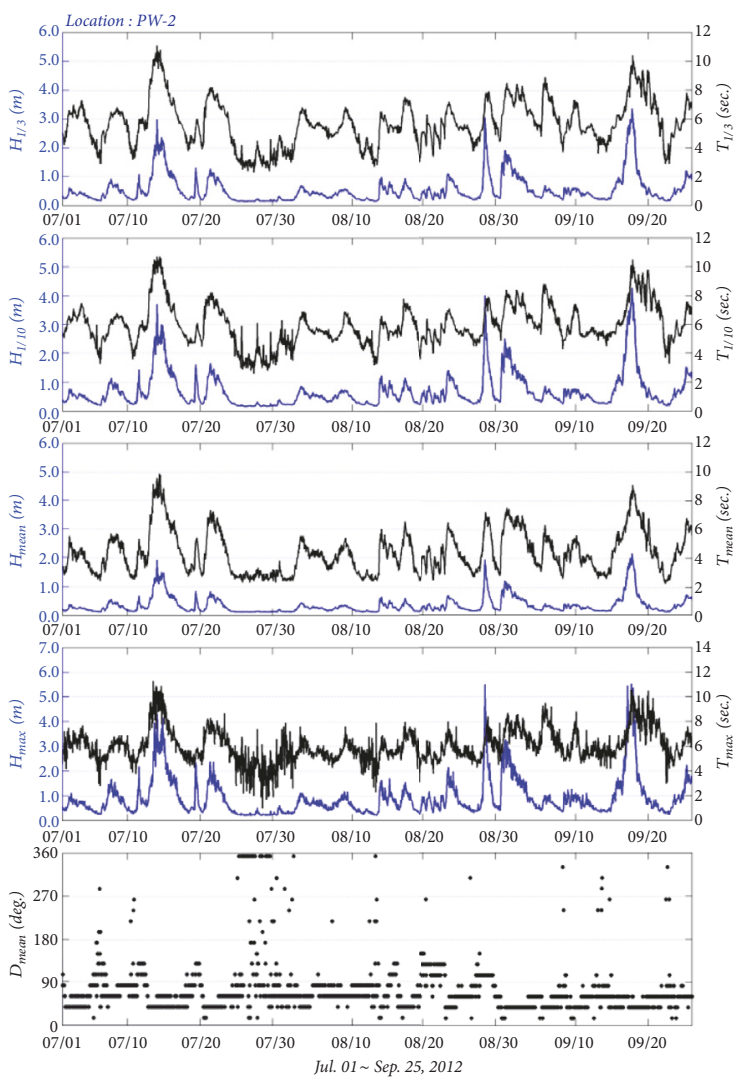

FIgURE 6: Time series data on W2 (2012.07 09).

result which is most similar to an actual phenomenon. Therefore, the target area was reproduced at a laboratory using the $1 / 80$ scale, and the location and size of the coastal structures were reproduced identically to the on-site condition. The model was intended to examine the physical phenomenon in the area behind the structures due to sediment transport by creating an erosive wave drawn from the observation result. The boundary of the model experiment is Area-C at Figure 1, where $\mathrm{X}$ is $3.6 \mathrm{~km}, \mathrm{Y}$ is $2.5 \mathrm{~km}$, and water depths up to $-35 \mathrm{~m}$ are reproduced. The conditions applied to the experiment are shown in Table 3.

3.2. Test Method. The experiment was conducted after setting up the sea bottom in a fixed condition, and it was confirmed whether the waves were reproduced to correspond to those observed in the field. The condition of abnormal high waves was selected among those observed at W2 (Figure 1) for the calibration of waves to be reviewed. The reason for selecting and reproducing the abnormal waves for the test is that the amount of sand in the target area moving to the north to be deposited at Area-A (Figure 1) is gradually increasing and the movement of sand is caused mostly by typhoons or abnormal high waves; this is because the sediment transport phenomenon clearly happens in autumn and winter season.

Regarding the sediment transport study, extensive research on movable tests has been conducted and is well known through the literature. While diverse empirical
TABLE 3: Test conditions.

\begin{tabular}{lcc}
\hline No & Items & Contents \\
\hline 1 & Scale & $1 / 80(\triangle \mathrm{X}=\triangle \mathrm{Y})$ \\
& Froude law \\
2 & Test Area & $35 \mathrm{~km} \times 25 \mathrm{~km}$ \\
3 & Depth & Up to $-35 \mathrm{~m}$ \\
4 & Bottom condition & Fixed bed: $-12 \mathrm{~m} \sim-35 \mathrm{~m}$ \\
& & Movable bed: $+5 \mathrm{~m} \sim-12 \mathrm{~m}$ \\
5 & $\mathrm{~d}_{50}$ (sand) & $0.1 \mathrm{~mm}$ \\
6 & Wave & Hs: $2 \sim 3 \mathrm{~m}, \mathrm{Ts}: 8 \sim 10 \mathrm{sec}$ \\
& & on the $-20 \mathrm{~m}$ of depth \\
7 & Measurement Item & (ENE dir.) \\
& & Wave deformation \\
\end{tabular}

TABLE 4: Wave conditions.

\begin{tabular}{lcccccc}
\hline Case & $\begin{array}{c}\mathrm{Hs} \\
(\mathrm{cm})\end{array}$ & $\begin{array}{c}\mathrm{Ts} \\
(\mathrm{sec})\end{array}$ & Structure & $\mathrm{C}$ & $\mathrm{F}_{0}$ & Remarks \\
\hline Case 1 & 2.50 & 0.89 & $\times$ & 6.07 & 2.63 & \\
Case 2 & 3.13 & 1.01 & $\times$ & 6.99 & 3.29 & \\
Case 3 & 3.75 & 1.12 & $\times$ & 7.83 & 3.95 & Accretion \\
Case 4 & 2.50 & 0.89 & $\mathrm{O}$ & 6.07 & 2.63 & Erosion \\
Case 5 & 3.13 & 1.01 & $\mathrm{O}$ & 6.99 & 3.29 & \\
Case 6 & 3.75 & 1.12 & $\mathrm{O}$ & 7.83 & 3.95 & \\
\hline
\end{tabular}

equations for the criteria on beaches eroded and sand deposited that have been suggested by Nayak [14], Dean [15], Sunamura and Horikawa [16], Hattori and Kawamata [17], and some others, (6) established by Dean and Sunamura and Horikawa, like (5), was employed in this study for the experiment to investigate whether any erosion occurred.

$$
\mathrm{F}_{0}=\frac{\mathrm{H}_{0}}{\left(\mathrm{~V}_{\mathrm{t}} \times \mathrm{T}\right)}
$$

$\mathrm{F}_{0}$ is the Dean Number, $\mathrm{H}_{0}$ is the deep-water wave height, $\mathrm{Vt}$ is the settlement velocity, and $\mathrm{T}$ is the wave period. When $\mathrm{F}_{0}<1$, accretion occurs, and when $\mathrm{F}_{0}>1$, erosion takes place [18].

$$
\mathrm{C}=\frac{\mathrm{H}_{0}}{\mathrm{~L}_{0}} \times(\tan \beta)^{0.27} \times\left(\frac{\mathrm{d}_{50}}{\mathrm{~L}_{0}}\right)^{-0.67}
$$

In (6), the value of $\mathrm{C}$ is a nondimensional coefficient determining erosion or sedimentation. $\mathrm{H}_{0}$ is the deep-water wave height, $L_{0}$ is the deep-water wave-length, $\tan \beta$ is the foreshore slope, and $d_{50}$ is the median diameter of particle. In the condition of model experiment, when $\mathrm{C}<4$, the sedimentation takes place; in the section of $4 \leq \mathrm{C} \leq 8$, erosion and sedimentation occur repeatedly; and when $C>9$, the erosion occurs [16].

Table 4 shows the modeled values considering erosive or accretion characteristics according to the condition of each wave based on the empirical equation. Also the current beach condition with emergency restoration completed was 
regarded as 'no structure' and the condition with an erosionpreventing facility installed for the purpose of protecting the relevant section was considered as 'structure'. When applied to (5), all cases are predicted as an erosion type while in (6) erosion and accretion were found to be taking place repeatedly.

In the target area, the waves approaching perpendicularly toward the beach have effect on the sediment transport. However, the fact that wave and current coexist to result in more sediment transport since the area has a long-shore current developing along the long shoreline, Hs: $3.75 \mathrm{~cm}$, Ts: $1.12 \mathrm{sec}$, in the Table 4 which is the most similar to the erosive wave, was employed for the movable-bed test.

The experiment results are representatively summarized by Cases 3 and 6 which have large amount of sand movement.

The 3D laser scanner is generally used for an on-site topographical survey [19-21], and topographical data is obtained by using a laser sensor and a wide-angle camera that were recently installed on the drone [22, 23]. However, up until now, no 3D scanner has been used for measurement in relation to movable-bed tests, and there has been little research to suggest that any accurate analysis results have been obtained.

In this study, a change in the sediment transport due to wave action was measured every 0.5 hour using the $3 \mathrm{D}$ laser scanner (Topcon, GLS-2000). It was judged that an accurate result would be obtained in comparison to the previous geographic survey result that was obtained by using a measuring pole. Table 5 shows the specifications of the $3 \mathrm{D}$ laser scanner used for this experiment.

3.3. Test Result. The experiment regarding wave deformation was conducted on the basis of the data obtained from the observations at W1 and W2. Wave calibration was performed with abnormal waves (erosive wave; Hs: $3.75 \mathrm{~cm}$, Ts: $1.12 \mathrm{sec}$ ) among various conditions. Measurements were carried out on each point of the foreshore area of the entire beach; however, this paper shows only the values reviewed at the spot of W2. Capacity type wave height meters (CHT6$60 \mathrm{E})$ were used for calibration with target wave heights and periods. 8192 data items of the wave with direction concentration ratio of 25 (Smax, peak value of spreading parameter) at the interval of $20 \mathrm{~Hz}$ were collected to conduct the analysis. The analysis results of Cases 3 and 6 out of experimental plans are shown in Figure 7, when the modified Bretschneider-Mitsuyasu type was employed for the spectrum.

When a wave propagates from offshore to near-shore, the wave energy changes according to the nonlinear interaction between water particles due to the shape of breakwater and change of water depth [24-26]. A relatively large energy distribution was established in a short-period area as shown in the experiment result. However, as the peak value and overall energy density of the spectrum were similar to the target values, the analyzed result was set as the wave signal. A total of 6 conditions were applied for the topographic change experiment. This paper describes the conditions of Cases 3 and 6 , both of which show a distinct tendency of sediment transport. The target area was reproduced with the sand of
TABLE 5: 3D-laser scanner specifications.

\begin{tabular}{lc}
\hline Items & Value \\
\hline (1) Size $(\mathrm{mm})$ & $228(\mathrm{D}) \times 293(\mathrm{~W}) \times 412(\mathrm{H})$ \\
$\begin{array}{l}\text { (2) Scan data rate } \\
\quad \text { Max. point per sec.) }\end{array}$ & $60,000 \sim 120,000$ \\
(3) Max. Point No. & $\mathrm{V}: 15,202 \mathrm{Pt} / \mathrm{Line}\left(270^{\circ}\right)$ \\
(4) Field of View & $\mathrm{H}: 20,268 \mathrm{Pt} / \mathrm{Line}\left(360^{\circ}\right)$ \\
(5) Angle Accuracy & $\mathrm{V}: 270^{\circ} / \mathrm{H}: 360^{\circ}$ \\
(6) Field Angle & $\mathrm{H}: 6^{\prime \prime} / \mathrm{V}: 6^{\prime \prime}$ \\
(7) Number of pixels & Wide : Diagonal $170^{\circ}$ \\
(8) Operating Temperature & Tele. : $8.9^{\circ}(\mathrm{V}) \times 11.9^{\circ}(\mathrm{H})$ \\
& $5 \mathrm{mega}$ pixels
\end{tabular}
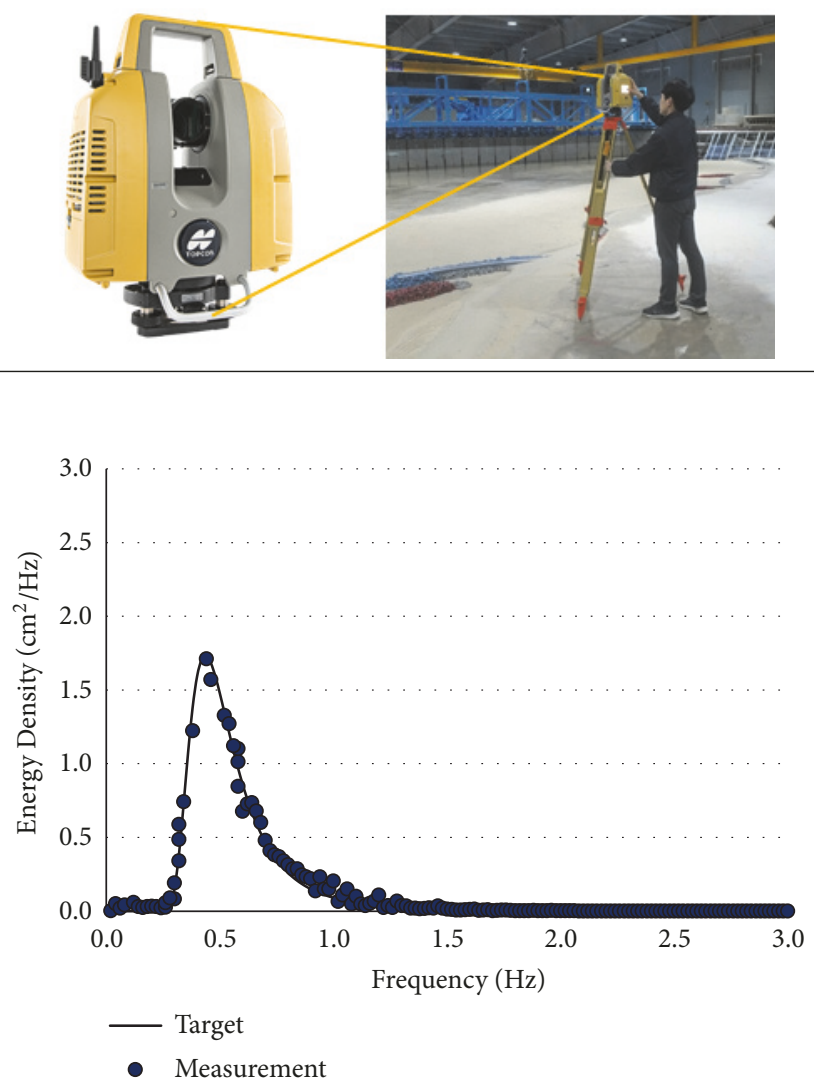

FIGURE 7: Wave calibration result of Cases 3 and 6 condition on the W2.

$\mathrm{d}_{50}: 0.1 \mathrm{~mm}$ from the water depth of $-10 \mathrm{~m}$, where the range applied to the experiment is described in Figure 8.

Before the experiment, to organize the same condition with real sea bottom condition, waves were generated for 10 minutes to make the sand ripple. After the application of the waves, tests were carried out every thirty minutes to assess out how much the topography had changed until 4.5 hours had elapsed. The camera mounted on the head of 3D scanner used for the movable-bed experiment was utilized for scanning of the area targeted for measurement, when the topographic changes were measured at the interval of $3 \mathrm{~mm}$ of $\mathrm{dx}$ and dy and, taking into consideration the shadowed 


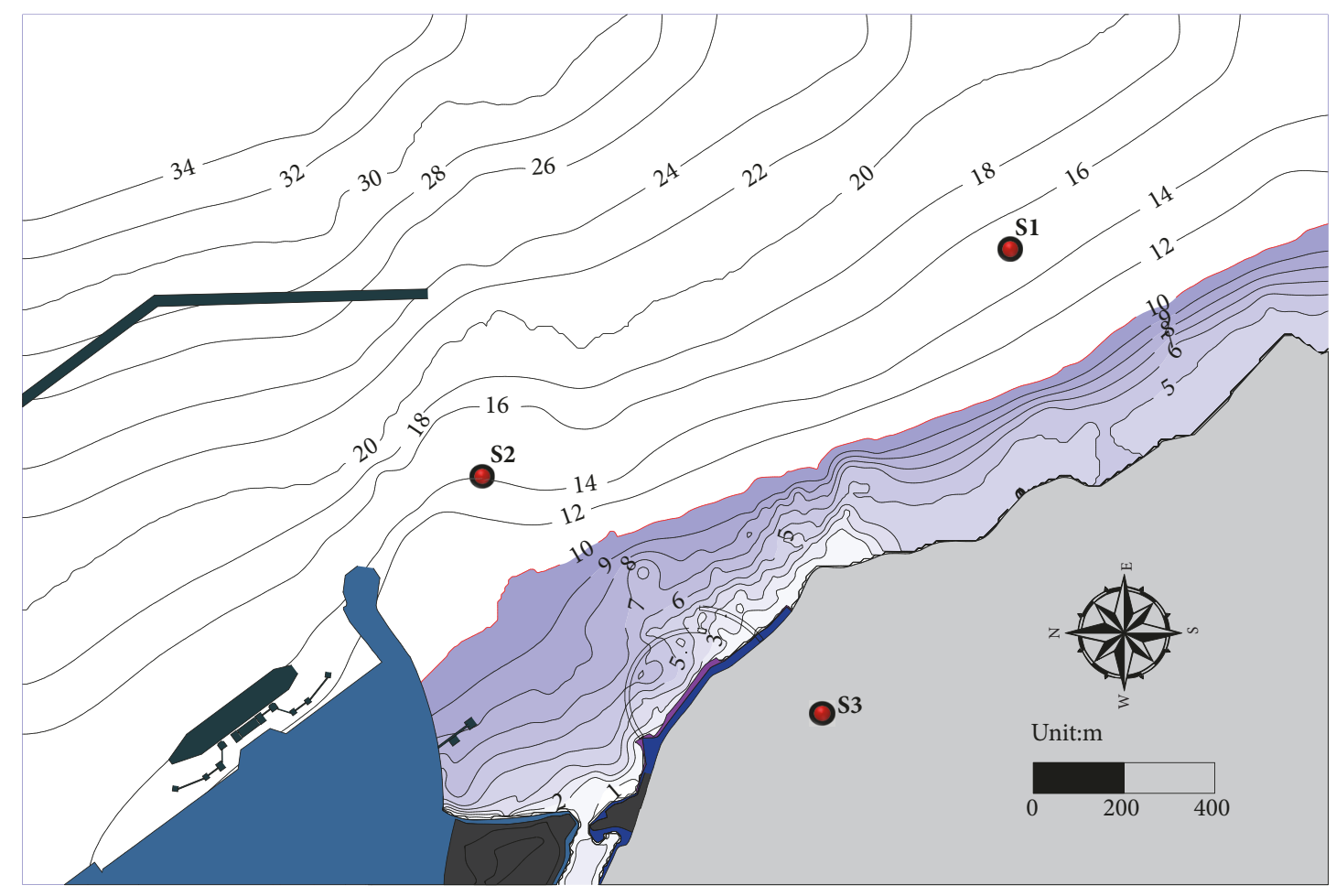

Figure 8: Test area for sediment transport test.

area which the laser did not reach, the measurement was conducted at S1 S3. The measured data of three location were integrated with Analysis Program (Recap 2018). This process was repeated at each time interval and for each test case. For the confirmation of the variation of sand movement, the difference was analyzed between the initial condition and the measured data Figures 9 and 10 show the analysis results. The experiment conducted in the condition when there is no structure led to erosion over the entire beach, and the long-shore sand was transferred toward the northern coast and the seaside to be deposited; the maximum erosion height was $40 \mathrm{~mm}$. In the condition where there was a structure in place to reduce erosion (Case 6), the sand movement on the southern beach was not much different compared to that of Case 3. However, erosion on the north was found to be much reduced, which indicates that the facility for preventing erosion is very effective for controlling the degree of sediment transport.

\section{Conclusion}

The erosion mechanism, which occurred due to the wave concentration and the long-shore current change in the back side of the structure when an erosive wave was deformed by a coastal structure, was analyzed. As seen in Figure 1, annual wave data was collected using an ultrasonic sensor and a pressure type sensor at 2 spots (W1 and W2) for test waves. The data analysis revealed that the incident waves toward the coast increased in autumn and winter compared to spring and summer, and the appearance rate of wave heights over $3 \mathrm{~m}$ also increased. In addition, the increased duration time

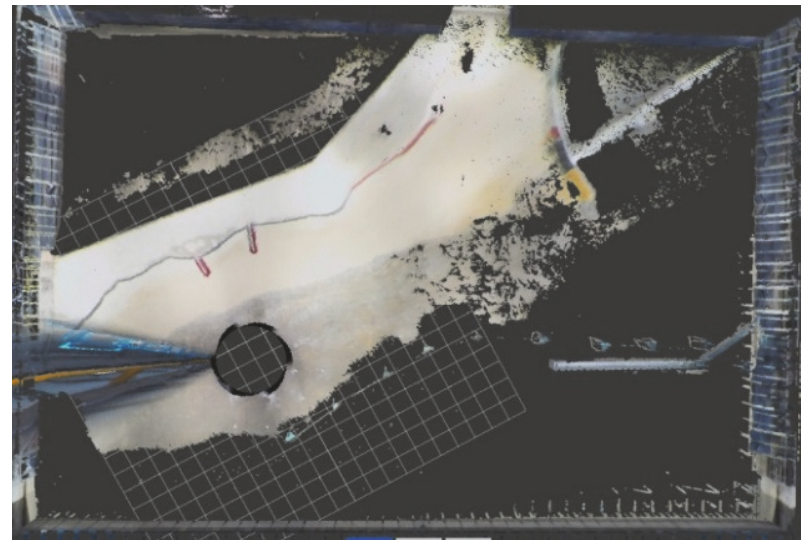

FIGURE 9: Scan data with camera of 3D scanner before bottom measurement (after ScanMaster program conversion).

of high incident waves was found to have effects in relation to the deformation of beaches.

The results of the sediment transport test indicate that erosion occurred over the entire beach and that the eroded sand moved toward the sea to form sand-bars.

Meanwhile, the shoreline regression was reproduced due to erosion in Area-B (Figure 1), where residential areas were highly congested. The experiment result showed that the corrosion that occurred in the target area was mainly caused by the wave concentration due to a large artificial structure installed on the shoreface and the strong long-shore current from Area-B to Area-A. As a countermeasure, an 

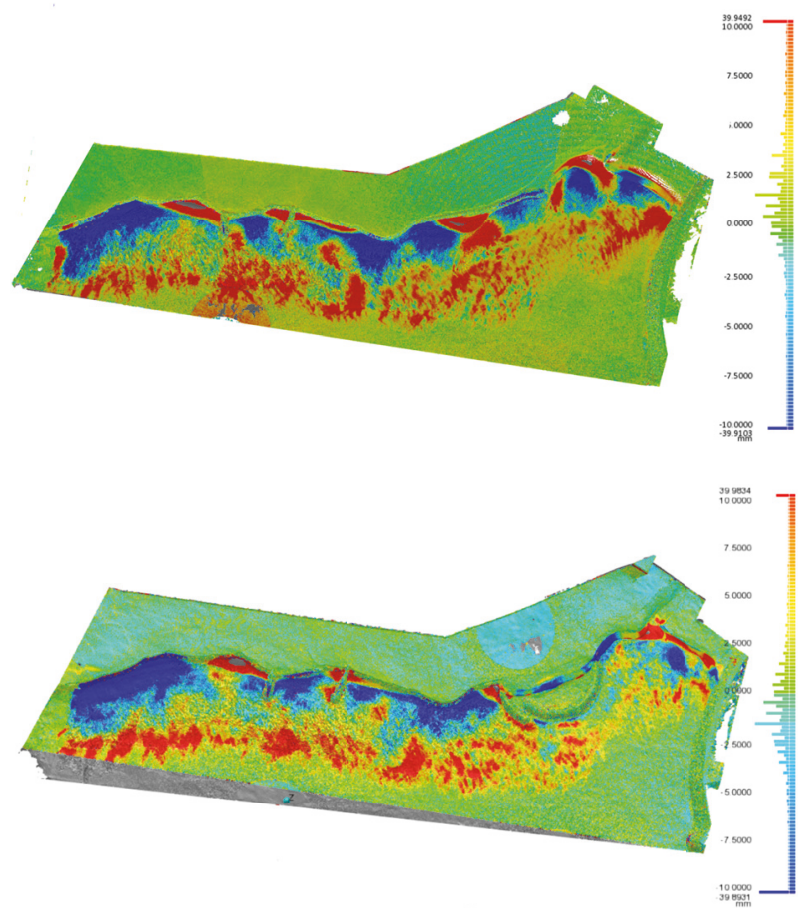

FIGURE 10: Topography change results after 4.5 hrs (up: no structure condition, bottom: structure installation condition).

erosion control facility was installed in order to control the wave concentration on Area-B and the long-shore current facing north. From the experiment result, the topographical change in Area-B (Figure 1) was mitigated and the amount of sediment transport that moved to Area-A was also reduced.

\section{Data Availability}

The data of field observation and physical model test used to support the findings of this study are included within the article.

\section{Conflicts of Interest}

The authors declare that they have no conflicts of interest.

\section{Acknowledgments}

This work was supported by Korea Gas Corporation (KOGAS) grant.

\section{References}

[1] J.-C. Liou, H.-K. Chang, W.-W. Chen, and S.-R. Liaw, "Beach erosion and preventive countermeasure at Kangnan coast, Taiwan," Journal of Coastal Research, vol. 25, no. 2, pp. 405-416, 2009.

[2] K. H. Kim and K. T. Shim, "A field investigation of waves and wave-induced currents at the youngrang coast of the Republic of Korea," Journal of Coastal Research, vol. 30, no. 72, pp. 6-10, 2014.
[3] N. C. Kraus and W. G. McDougal, "The effects of seawalls on the beach: Part I, an updated literature review," Journal of Coastal Research, vol. 12, no. 3, pp. 691-701, 1996.

[4] K.-H. Kim, K.-T. Shim, and B. Shin, "Morphological change near artificial reefs as a beach erosion countermeasure," Journal of Coastal Research, vol. 1, no. 75, pp. 403-407, 2016.

[5] K. Kim, H. Yoo, and N. Kobayashi, "Mor-phological change near artificial reefs as a beach erosion," Journal of Coastal Research, vol. 27, no. 4, pp. 645-651, 2011.

[6] M. C. Marimon, G. Tangonan, N. J. Libatique, and K. Sugimoto, "Development and evaluation of wave sensor nodes for ocean wave monitoring," IEEE Systems Journal, vol. 9, no. 1, pp. 292302, 2015.

[7] B. Magnell, L. Ivanov, and E. Siegel, "Measurements of ice parameters in the Beaufort Sea using the Nortek AWAC acoustic Doppler current profiler," in Proceedings of the MTS/IEEE Seattle, OCEANS 2010, pp. 1-8, USA, September 2010.

[8] B. H. Kang and K. H. Kim, "Wave data analysis for wave energy power in Namae coast," Applied Mechanics and Materials, vol. 672-674, pp. 446-452, 2014.

[9] O. Burvingt, G. Masselink, P. Russell, and T. Scott, "Classification of beach response to extreme storms," Geomorphology, vol. 295, pp. 722-737, 2017.

[10] H. Karunarathna, J. Brown, A. Chatzirodou, P. Dissanayake, and P. Wisse, "Multi-timescale morphological modelling of a dunefronted sandy beach," Coastal Engineering Journal, vol. 136, pp. 161-171, 2018.

[11] J. L. Irish, P. J. Lynett, R. Weiss, S. M. Smallegan, and W. Cheng, "Buried relic seawall mitigates Hurricane Sandy's impacts," Coastal Engineering Journal, vol. 80, pp. 79-82, 2013.

[12] F. E. Karathanasi and K. A. Belibassakis, "A cost-effective method for estimating long-term effects of waves on beach erosion with application to Sitia Bay, Crete," Oceanologia, vol. 61, no. 2, pp. 276-290, 2019.

[13] K.-H. Kim and A. Y. W. Widayati, "Study on alternatives of sand placement method for beach nourishment project," KSCE Journal of Civil Engineering, vol. 16, no. 4, pp. 478-485, 2012.

[14] I. V. Nayak, "Equilibrium profiles of model beaches," in Proceedings of the 12th International Conference on Coastal Engineering, pp. 1321-1340, Washington, DC, USA, 1970.

[15] R. G. Dean, "Heuristic models of sand transport in the surf zone," in Proceedings of Conference on Engineering Dynamics in the Surf Zone, pp. 208-214, 1973.

[16] T. Sunamura and K. Horikawa, "Two-dimensional beach transformation due to waves," in Proceedings of 14th Conference on Coastal Engineering, pp. 920-938, 1974.

[17] M. Hattori and R. Kawamata, "Onshore-offshore transport and beach profile change," in Proceedings of 17th Conference on Coastal Engineering, pp. 254-255, 1980.

[18] Shore Protection Manual, vol. 2, U.S Army Engineer Waterways Experiment Station, Coastal Engineering Research Center, U.S. Government Printing Office, Washington, DC, USA, 4th edition, 1984.

[19] G. Colangelo and A. Guariglia, "A combined methodology for landslide risk mitigation in basilicata region by using LIDAR technique and rockfall simulation," International Journal of Geophysics, vol. 2011, Article ID 392676, 5 pages, 2011.

[20] L. Di Liberto, F. Angelini, I. Pietroni et al., "Estimate of the arctic convective boundary layer height from lidar observations: a case study," Advances in Meteorology, vol. 2012, Article ID 851927, 9 pages, 2012. 
[21] B.-H. Jun, "Numerical simulation of the topographical change in Korea mountain area by intense rainfall and consequential debris flow," Advances in Meteorology, vol. 2016, Article ID 9363675, 11 pages, 2016.

[22] R. Martínez Marín, E. Lianes Revilla, J. C. Ojeda Manrique, and M. Marchamalo Sacristán, "Handling low-density LiDAR data: calculating the heights of civil constructions and the accuracy expected," Advances in Civil Engineering, vol. 2013, Article ID 602364, 5 pages, 2013.

[23] K. M. Brubaker, W. L. Myers, P. J. Drohan, D. A. Miller, and E. W. Boyer, "The use of LiDAR terrain data in characterizing surface roughness and microtopography," Applied and Environmental Soil Science, vol. 2013, Article ID 891534, 13 pages, 2013.

[24] D. Carevic, G. Loncar, and M. Prsic, "Wave parameters after smooth submerged breakwater," Coastal Engineering Journal, vol. 79, pp. 32-41, 2013.

[25] N. Kobayashi, "Review of wave transformation and cross-shore sediment transport processes in surf zones," Journal of Coastal Research, vol. 4, no. 3, pp. 435-445, 1988.

[26] H. F. Stockdon, R. A. Holman, P. A. Howd, and A. H. Sallenger Jr., "Empirical parameterization of setup, swash, and runup," Coastal Engineering Journal, vol. 53, no. 7, pp. 573-588, 2006. 


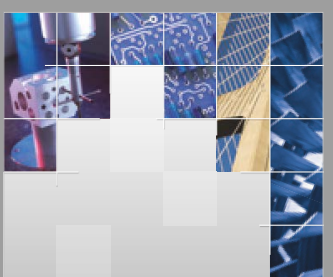

\section{Enfincering}
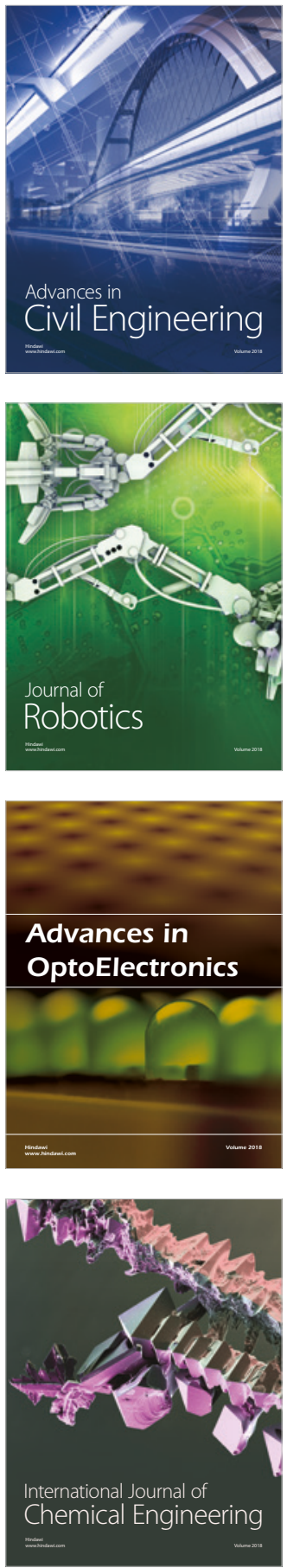

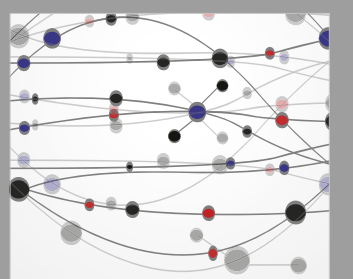

\section{Rotating \\ Machinery}

The Scientific World Journal

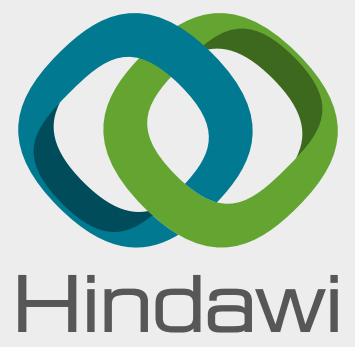

Submit your manuscripts at

www.hindawi.com
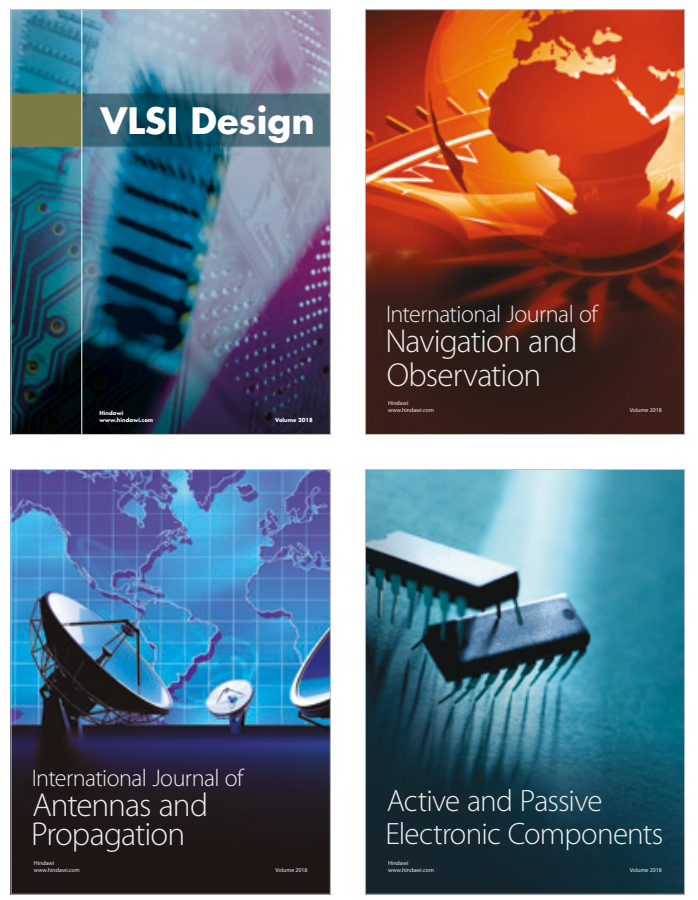
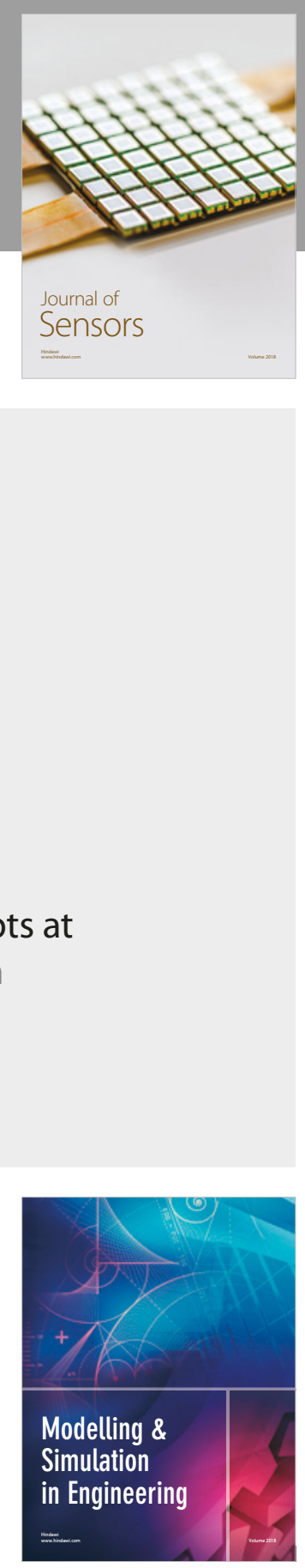

\section{Advances \\ Multimedia}
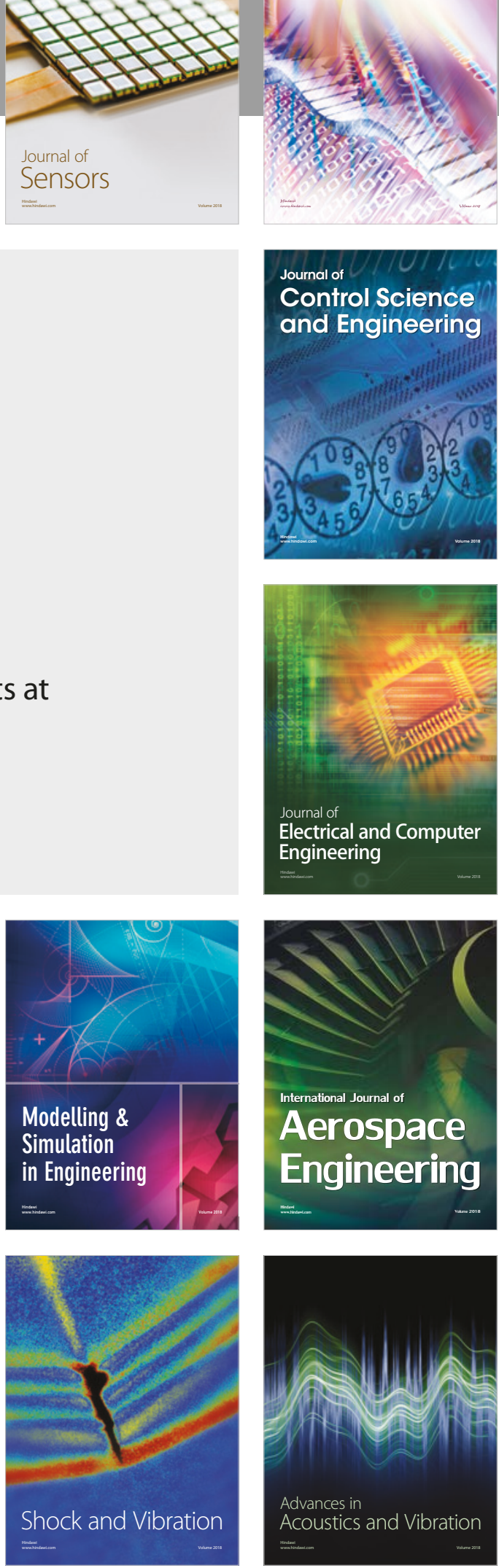